\title{
Positive exercise test?
}

\author{
W. K. den Dekker ${ }^{1}$ J. W. Deckers ${ }^{1}$ S. C. Yap ${ }^{1}$
}

Published online: 12 July 2016

(c) The Author(s) 2016. This article is available at SpringerLink with Open Access

A 46-year-old male was referred for exercise testing after he was evaluated in the emergency department because of progressive fatigue, dyspnoea on exertion and chest pain with tingling of the left arm. He was an otherwise healthy man who was a professional climber. He had no cardiovascular risk factors and was not using any medication. On physical examination he was normotensive and the cardiovascular examination was normal. His troponin level was normal. A bicycle exercise test was performed to rule out ischaemia. He exercised for $13 \mathrm{~min}$ and $40 \mathrm{sec}$, reaching 242 Watt (reference value 208 Watt) with a maximum heart rate of 167 beats/min ( $96 \%$ of predicted maximal heart rate) and a blood pressure of $187 / 92 \mathrm{mmHg}$. The test was stopped because of fatigue. He had no chest pain. Two recordings of the exercise test are shown here (Fig. 1a, b).

\section{Questions}

Is this a positive test for ischaemia? What is the prognosis?

\begin{abstract}
Answer
You will find the answer elsewhere in this issue.

Open Access This article is distributed under the terms of the Creative Commons Attribution 4.0 International License (http:// creativecommons.org/licenses/by/4.0/), which permits unrestricted use, distribution, and reproduction in any medium, provided you give appropriate credit to the original author(s) and the source, provide a link to the Creative Commons license, and indicate if changes were made.
\end{abstract}

W. K. den Dekker

w.dendekker@erasmusmc.nl

1 Department of cardiology, Thoraxcenter, ErasmusMedical

Center, Rotterdam, The Netherlands 


\section{Advertisement placed here.}

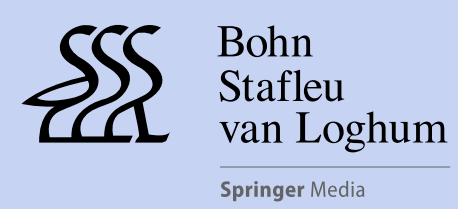

Houten 2016 


\section{Advertisement placed here.}

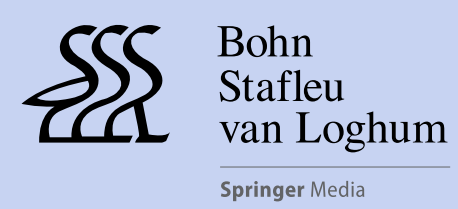

Houten 2016 
a

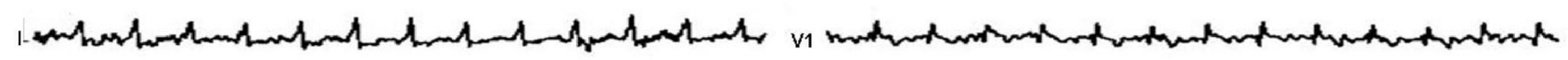

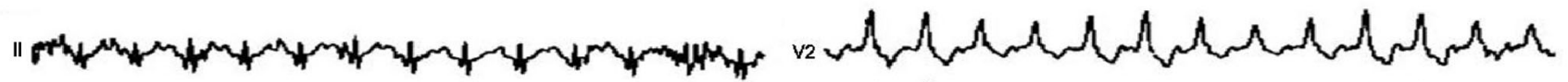

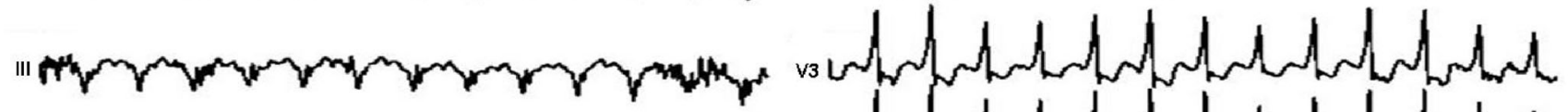

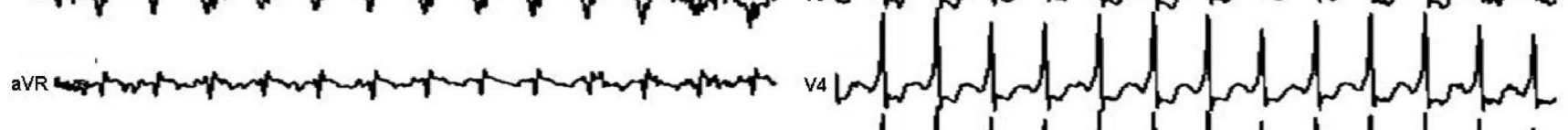
ave aV

b I

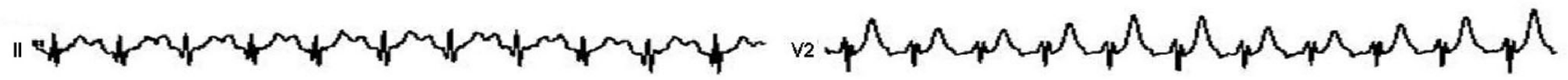

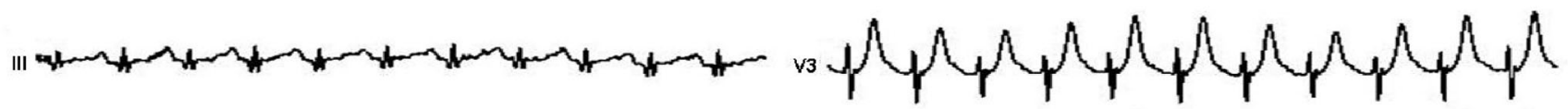

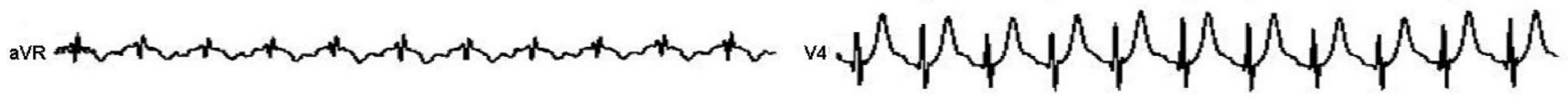

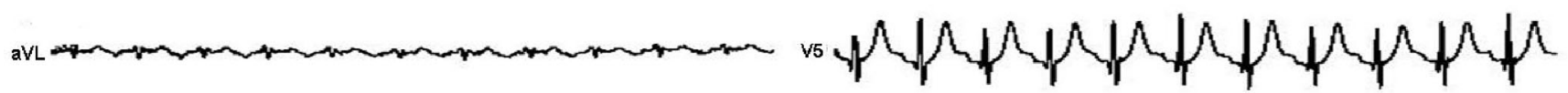

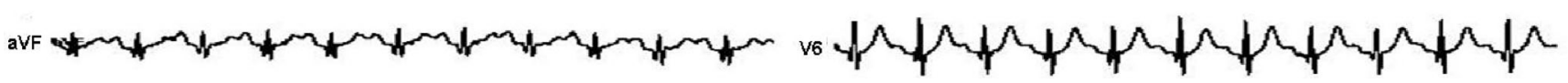

Fig. 1 a During exercise, b Recovery phase 